\title{
TÁC ĐộNG CỦA CHẤT LƯợNG DỊCH VỤ ĐẾN LÒNG TRUNG THÀNH CỦA KHÁCH HÀNG SỬ DỤNG ADSL TẠI TP.HCM PGS.TS. Hà Nam Khánh Giao ${ }^{1}$ - ThS Trần Hữu Ái ${ }^{2}$
}

\section{TÓM TĂT}

Nghiên cứu này xem xét mối quan hẹ giũa lòng trung thành của khách hàng và các yếu tố chất lương dịch vu ADSL, bằng việc khảo sát 289 khách hàng tại TPHCM. Thang đo SERVPERF (Cronin \& Taylor, 1992) được sử dụng có điều chỉnh, phuơng pháp phân tích độ tin cậy Cronbach's Alpha, phân tích nhân tố khám phá EFA, cùng với phân tích hồi quy.

Kết quả cho thấy chất lượng dịch vu ADSL được đo bằng 6 thành phần được thể hiện theo thư tự tầm quan trọng: (1) Cảm nhận giá cả, (2) Năng lực phục vụ, (3) Phuoong tiện hữu hình, (4) Giá trị gia tăng tiện ích, (5) Khả năng đáp ứng, (6) Độ tin cây; và sư thỏa mãn của khách hàng ảnh hưởng tỷ lệ thuận với lòng trung thành dịch vu. Nghiên cứu đề ra một số kiến nghị cho ban lãnh đạo các doanh nghiệp cung ưng dịch vu ADSL nhằm nâng cao chất lương dịch vu để làm tăng lòng trung thành khách hàng.

Từ khóa: ADSL, chất lượng dịch vụ, độ thỏa mãn, lòng trung thành

\section{THE INFLUENCE OF SERVICE QUALITY ON THE CUSTOMERS LOYALTY USING ADSL AT HOCHIMINH CITY}

\section{ABSTRACT}

This research studies the relationship between customers' loyalty and the factors of ADSL service quality, by surveying 289 customers at HoChiMinh city (HCMC). The scale SERVPERF (Cronin \& Taylor, 1992) were used correctly, together with Cronbach's Alpha credibility analysis, exploratory factor analysis (EFA), and linear regression analysis.

The results shows that ADSL service quality is measured by 06 main factors, arranged by the decreasing importance: (1) Perceived price, (2) Service capabilities, (3) Tangibles, (4) Value added facility, (5) Assurance, (6) Reliability; and customer satisfaction is favorably correlated to service loyalty. The research reveals some suggestions to ADSL service providers' management in order to enhance service quality to improve customer loyalty.

Keywords: ADSL, service quality, satisfaction, loyalty

\section{KHÁI QUÁT}

Tính đến tháng 7/2011, Việt Nam có khoảng 29,5 triệu người đang sử dụng Internet, chiếm 33,99\% dân số, dự báo sẽ tăng lên 40\% vào năm 2012 (www.thongkeinternet.vn). Khoảng $62 \%$ người sử dụng Việt Nam truy cập Internet mỗi ngày, và trung bình mỗi ngày dành 140 phút trên Internet (Ở TPHCM là 150 phút) (www.vecita.gov.vn). Hiện nay, chất lượng dịch vụ $\mathrm{ADSL}$ được đo lường chủ yếu dựa trên các yếu tố kỹ thuật bằng các kết quả đo kiểm của Cục quản lý Chất lượng, Bộ Thông tin và Truyền thông theo tiêu chuẩn ngành (Tiêu chuẩn Ngành TCN 68-227: 2006 "Dịch vụ truy nhập Internet ADSL - Tiêu chuẩn chất lượng”).

\footnotetext{
$\checkmark \quad{ }^{1}$ Trưởng Khoa Du Lịch, Trường Đại Học Tài chính- Marketing, Bộ Tài chính.

$\checkmark \quad$ Điện thoại di động: 0903306363

$\checkmark$ e-mail: khanhgiaohn@yahoo.com

$\checkmark$ Địa chỉ liên lạc thư từ: 243 Hùynh văn Bánh, Phường 12, Quận Phú Nhuận, TPHCM

$\checkmark \quad$ Định hướng nghiên cứu: kinh doanh quốc tế, marketing dịch vụ, du lịch

$\checkmark \quad 2$ Thành viên hội đồng quản trị, Cty cổ phần thiết kế AN LỘC PHÚC, 369A Lê Quang Định, P.5, Q. Bình Thạnh, TPHCM

$\checkmark$ Địa chỉ liên lạc thư từ: 273/72 Nguyễn Văn Đậu, P.11, Q. Bình Thạnh, TPHCM

$\checkmark$ Email: aihuutran@gmail.com

$\checkmark$ Điện thoại di động: 0985164753
} 
Việt Nam hiện có nhiều nhà cung cấp dịch vụ Internet băng rộng: Tập đoàn Bưu chính Viễn thông Việt Nam (VNPT) chiếm trên 70\% thị trường, Tổng Công ty Viễn thông Quân đội (Viettel) chiếm $18 \%$, Công ty Đầu tư và Phát triển Công nghệ (FPT) chiếm $7 \%$, Công ty Cổ phần Dịch vụ Bưu chính Viễn thông Sài Gòn (SPT), Công ty Thông tin Viễn thông Điện lực (EVN Telecom), Công ty Cổ phần NetNam, ... (www.thongkeinternet.vn ). Muốn đạt được mục tiêu thu hút khách hàng sử dụng dịch vụ, giữ chân được khách hàng cũ và cạnh tranh được các đối thủ cùng ngành, doanh nghiệp cung cấp dịch vụ phải không ngừng nâng cấp cơ sở hạ tầng, nâng cao chất lượng kỹ thuật và chất lượng dịch vụ. Hiện nay, chất lượng kỹ thuật của dịch vụ gần như khó có tính đột phá trong cạnh tranh, vậy nên doanh nghiệp cung cẩp cần chú trọng nhiều hơn đến chất lượng dịch vụ.

\section{CƠ SỞ LÝ THUYẾT VÀ MÔ HÌNH NGHIÊN CÚU \\ Về chất lượng dịch vụ}

Tổ chức quốc tế về Tiêu chuẩn hóa ISO, trong dự thảo DIS 9000:2000 đã đưa ra định nghĩa "Chất lượng là khả năng tập hợp các đặc tính của một sản phẩm, hệ thống hay quá trình để đáp ứng các yêu cầu của khách hàng và các bên có liên quan". Parasuraman \& ctg (1985) cho rằng Chất livơng dịch vu được xem là kết quả của sự so sánh của khách hàng, được tạo ra giữa sự mong đợi của họ về dịch vụ đó và sự cảm nhận của họ khi sử dụng dịch vụ đó.

Từ đó, Parasuraman \& ctg (1991) đã đề xuất thang đo SERVQUAL để đánh giá chất lượng dịch vụ gồm 22 biến thuộc 5 thành phần (Tin cậy, Đáp ứng, Phương tiện hữu hình, Năng lực phục vụ, Đồng cảm) để đo lường chất lượng kỳ vọng và dịch vụ cảm nhận, có thể được ứng dụng cho mọi loại hình dịch vụ. Cronin \& Taylor (1992) đưa ra thang đo SERVPERF, một thang đo tốt trong việc đo lường chất lượng dịch vụ, theo hướng lý thuyết thỏa mãn khách hàng.

\section{Quan hệ chất lượng dịch vụ, giá cả và sự thỏa mãn của khách hàng}

Trong khi ảnh hưởng của giá tác động vào sự hài lòng khách hàng ít nhận được sự quan tâm của các nhà nghiên cứu, Zeithaml \& Bitner (2000) cho rằng giá của dịch vụ có thể ảnh hưởng rất lớn vào nhận thức về chất lượng dịch vụ, sự hài lòng và giá trị. Nghiên cứu này định nghĩa và đo lường khái niệm giá cả dịch vụ dưới góc độ là cảm nhận hài lòng. Do thành phần giá cả dịch vụ được khách hàng đánh giá dựa trên cảm nhận hài lòng giá cả một cách chủ quan của họ so với giá cả dịch vụ của các nhà cung cấp khác, nên cảm nhận giá cả được đo lường dựa trên các đặc điểm giá cước dịch vụ ADSL. Nghiên cứu xây dựng thang đo thành phần cảm nhận giá cả dựa trên thảo luận nhóm với các chuyên gia trong ngành về đặc điểm giá cước dịch vụ ADSL.

Giao \& Vũ (2011) đúc kết đơn giản về sự thỏa mãn khách hàng như là điểm gặp nhau hay diện tích trùng nhau giữa khả năng của doanh nghiệp và nhu cầu của khách hàng; hay là mức độ trạng thái cảm giác của một người bắt đầu từ việc so sánh kết quả thu được từ sản phẩm/dịch vụ với những kỳ vọng của người đó.

Nhiều nghiên cứu cho thấy chất lượng dịch vụ và sự thỏa mãn nhu cầu khách hàng là hai khái niệm phân biệt, song rất ít nghiên cứu tập trung vào việc kiểm định mức độ giải thích của các thành phần chất lượng dịch vụ đối với sự thỏa mãn khách hàng (Lassar \& ctg, 2000). Zeithaml \& Bitner (2000) xem chất lượng dịch vụ như là một yếu tố tác động vào sự thỏa mãn của khách hàng.

Hình 1: Mối quan hệ giữa chất lượng dịch vụ và sự thỏa mãn khách hàng

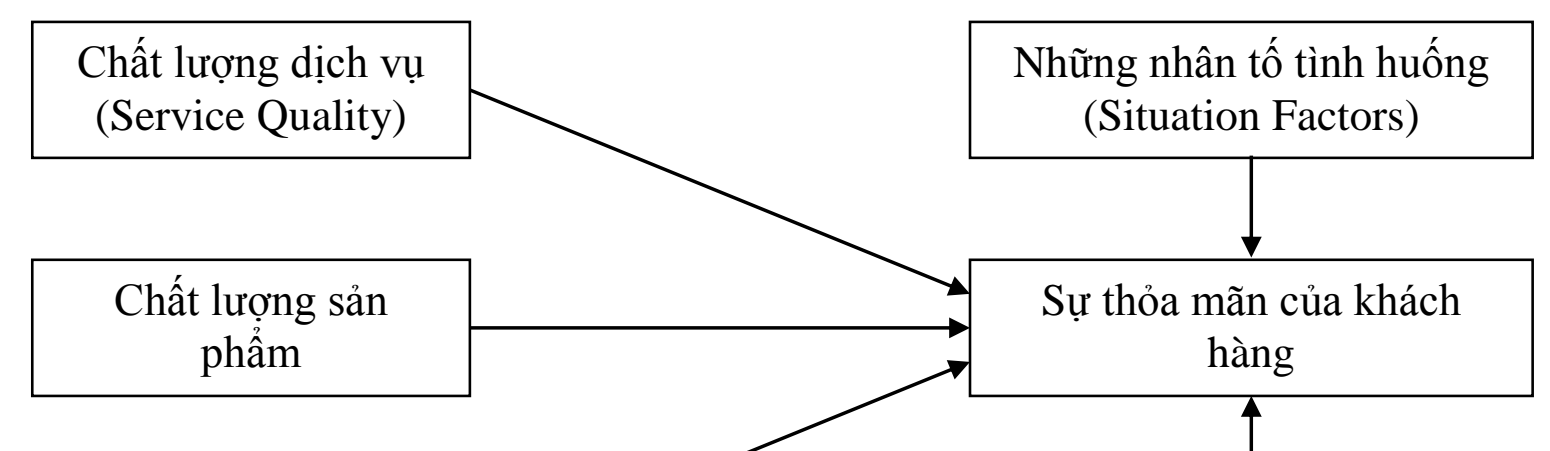


Nguồn: Zeithaml \& Bitner (2000), Services Marketing, McGraw-Hill.

\section{Quan hệ giữa sự thỏa mãn và lòng trung thành dịch vụ}

Lòng trung thành dịch vụ được định nghĩa là "Mức độ mà một khách hàng biểu lộ hành vi mua lặp lại sản phẩm từ một nhà cung cấp dịch vụ, chiếm hữu một khuynh hướng thái độ tích cực đổi với nhà cung cấp, và khi một nhu cầu của dịch vụ đó tồn tại, thì họ chỉ xem xét sử dụng nhà cấp dịch vụ này mà thôi" (Gremler \& Brown, 1996).

Nghiên cứu này xem xét mối quan hệ giữa giá cả, chất lượng dịch vụ ADSL và lòng trung thành của khách hàng. Theo Zeithaml \& ctg (1996), chất lượng dịch vụ ảnh hưởng tới lòng trung thành của khách hàng sử dụng dịch vụ, khách hàng thỏa mãn có xu hướng sử dụng dịch vụ nhiều và thường xuyên hơn, có xu hướng tiếp tục mua và truyền miệng về dịch vụ.

Too \& ctg (2001) đề xuất thang đo lòng trung thành dịch vụ gồm 3 biến quan sát hành vi và 8 biến quan sát thái độ, trong nghiên cứu này, sau khi nghiên cứu định tính, đã loại bỏ 7 biến vì không phù hợp với loại hình dịch vụ ADSL, như vậy, thang đo lòng trung thành dịch vụ ADSL tại TPHCM gồm 4 biến quan sát.

Mô hình nghiên cứu đề nghị được xây dựng trên cơ sở các tiền đề lý thuyết nêu trên, và thực tiễn kinh doanh ADSL tại TPHCM, và được thể hiện trong hình 2.

\section{Hình 2: Mô hình nghiên cứu đề nghị}

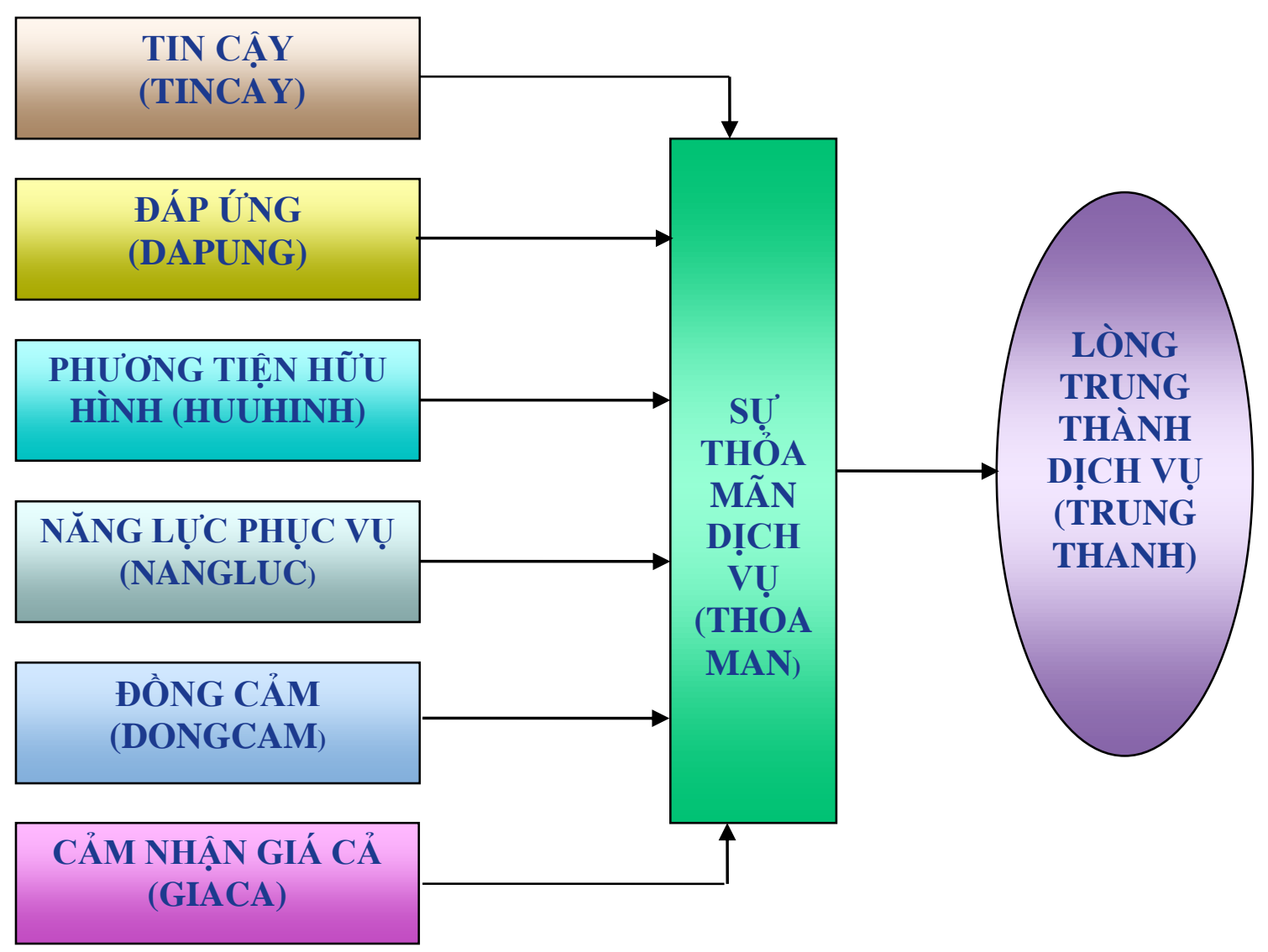




\section{THỰC HIỆN NGHIÊN CÚU}

\section{Khảo sát}

Cuộc khảo sát được thực hiện trong năm 2011, 350 bảng câu hỏi trực tiếp đã được phát ra, song song với khảo sát qua mạng (công cụ google Docs), kết quả thu về 328 bảng (276 trực tiếp, 52 qua mạng), 39 bảng bị loại do thông tin không đầy đủ, cuối cùng còn lại 289 bảng được sử dụng cho phân tích.

\section{Mẫu nghiên cứu}

Tỷ lệ nam- nữ trong mẫu khá chênh lệch với 204 nam (70.6 \%) - 85 nữ (29.4\%). Bảng 1,2 và 3 lần lượt thể hiện cấu trúc mẫu khảo sát theo nhà cung cấp dịch vụ, theo độ tuổi, và theo mục đích sử dụng chính của dịch vụ ADSL.

Bảng 1: Cấu trúc mẫu khảo sát theo nhà cung cấp dịch vụ

\begin{tabular}{|c|c|c|c|c|c|}
\hline & VNPT & VIETTEL & FPT & $\begin{array}{c}\text { Doanh Nghiệp } \\
\text { khác }\end{array}$ & Tổng \\
\hline Tần số & 210 & 44 & 20 & 15 & 289 \\
\hline Tỷ lệ \% & 72.60 & 15.40 & 6.90 & 5.10 & 100 \\
\hline
\end{tabular}

Bảng 2: Cấu trúc mẫu khảo sát theo độ tuổi

\begin{tabular}{|c|c|c|}
\hline Độ tuổi & Tần số & Tỷ lệ \% \\
\hline Đến 20 & 53 & 18.3 \\
\hline Từ 21 đến 35 & 217 & 75.1 \\
\hline Từ 36 đến 45 & 15 & 5.2 \\
\hline Trên 46 & 4 & 1.4 \\
\hline Tổng & $\mathbf{2 8 9}$ & $\mathbf{1 0 0}$ \\
\hline
\end{tabular}

Bảng 3: Mục đích sử dụng dịch vụ của khách hàng

\begin{tabular}{|c|c|c|}
\hline Mục đích chính sử dụng dịch vụ & Tần số & Tỷ lệ \% \\
\hline Công việc & 40 & 13.8 \\
\hline Trao đổi liên lạc & 38 & 13.2 \\
\hline Học tập, nghiên cứu & 139 & 48.1 \\
\hline Giải trí & 69 & 23.9 \\
\hline Mục đích khác & 3 & 1.0 \\
\hline Tổng & 289 & 100 \\
\hline
\end{tabular}

\section{Kiểm định thang đo và mô hình đo lường}

Bảng 4 cho thấy hệ số Cronbach's Alpha của tất cả các thang đo đều lớn hơn 0.7 , các hệ số tương quan biến-tổng đều lớn hơn 0.3 , do đó tất cả các thang đo đều được sử dụng trong bước phân tích EFA và hồi qui tiếp theo (Nunnally \& Burnstein, 1994).

Bảng 4: Kết quả kiểm định Cronbach's Alpha các thang đo

\begin{tabular}{|c|c|c|c|c|}
\hline STT & THANG DO & $\begin{array}{c}\text { Só } \\
\text { BIẾN } \\
\text { QUAN } \\
\text { SÁT }\end{array}$ & $\begin{array}{c}\text { CRONBACH'S } \\
\text { ALPHA }\end{array}$ & 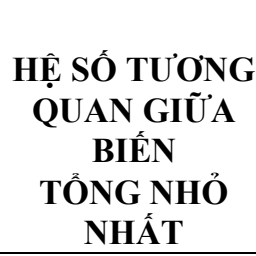 \\
\hline 1 & Phương tiện hữu hình (HUUHINH) & 5 & 0.788 & 0.601 \\
\hline 2 & Năng lực (NANGLUC) & 4 & 0.825 & 0.620 \\
\hline 3 & Sự đáp ứng (DAPUNG) & 4 & 0.784 & 0.424 \\
\hline 4 & Giá cả cảm nhận (GIACA) & 3 & 0.783 & 0.568 \\
\hline 5 & Sự đồng cảm (DONGCAM) & 3 & 0.743 & 0.532 \\
\hline
\end{tabular}




\begin{tabular}{|l|l|l|l|l|}
6 & Sự Tin cậy (TINCAY) & 3 & 0.708 & 0.339 \\
\hline 7 & Sự thỏa mãn của khách hàng (THOAMAN) & 4 & 0.776 & 0.656 \\
\hline 8 & Lòng trung dịch vụ (TRUNGTHANH) & 4 & 0.701 & 0.781 \\
\hline
\end{tabular}

Kết quả phân tích nhân tố khám phá (Bảng 5 ) cho thấy 26 biến quan sát trong 5 thành phần được phân bổ lại thành 6 nhân tố, 22 biến trong thang đo chất lượng dịch vụ ADSL tại TPHCM và 1 nhân tố đo lường cảm nhận giá cả. Nhân tố thứ 6 là nhân tố giá trị gia tăng tiện ích (GTGT), có những yếu tố mang tính chất kỹ thuật phục vụ đưa các giá trị tiện ích đến khách hàng trên nền ADSL. Hệ số $\mathrm{KMO}=0.718$ nề $\mathrm{EFA}$ phù hợp với dữ liệu, thống kê Chi-quare của kiểm định Bertlett đạt giá trị 4.009E3 với mức ý nghĩa 0.000 ; do vậy các biến quan sát có tương quan với nhau xét trên phạm vi tổng thể. Phương sai trích $69.434 \%$ thể hiện rằng 7 nhân tố rút ra giải thích được $69.434 \%$ biến thiên của dữ liệu, tại hệ số eigenvalue bằng 1.128. Các nhân tố trích ra đều đạt độ tin cậy và độ giá trị.

Bảng 5: Kết quả EFA các thành phần thang đo chất lượng dịch vụ và giá cả cảm nhận

\begin{tabular}{|c|c|c|c|c|c|c|c|}
\hline \multirow[b]{2}{*}{$\begin{array}{c}\text { BIẾN QUAN } \\
\text { SÁT }\end{array}$} & \multicolumn{7}{|c|}{ NHÂN TỐ } \\
\hline & $\begin{array}{c}1 \\
(\text { HUU } \\
\text { HINH) } \\
\end{array}$ & $\begin{array}{c}2 \\
(\mathrm{NANG} \\
\text { LUC) } \\
\end{array}$ & $\begin{array}{c}3 \\
(G T G T)\end{array}$ & $\begin{array}{c}4 \\
\text { (DAP } \\
\text { UNG) }\end{array}$ & $\begin{array}{c}5 \\
(\mathrm{GIA} \\
\text { CA }) \\
\end{array}$ & $\begin{array}{c}6 \\
\text { (DONG } \\
\text { CAM) } \\
\end{array}$ & $\begin{array}{c}7 \\
(\mathrm{TIN} \\
\text { CAY) } \\
\end{array}$ \\
\hline HUUHINH1 & .782 & & & & & & \\
\hline HUUHINH2 & .707 & & & & & & \\
\hline HUUHINH3 & .663 & & & & & & \\
\hline HUUHINH4 & .544 & & & & & & \\
\hline HUUHINH5 & .601 & & & & & & \\
\hline NANGLUC1 & & .825 & & & & & \\
\hline NANGLUC2 & & .737 & & & & & \\
\hline NANGLUC3 & & .810 & & & & & \\
\hline NANGLUC4 & & .792 & & & & & \\
\hline TINCAY5 & & & .925 & & & & \\
\hline DONGCAM1 & & & .903 & & & & \\
\hline DONGCAM6 & & & .901 & & & & \\
\hline TINCAY1 & & & & .816 & & & \\
\hline DAPUNG1 & & & & .632 & & & \\
\hline DAPUNG2 & & & & .845 & & & \\
\hline DAPUNG3 & & & & .587 & & & \\
\hline GIACA1 & & & & & .635 & & \\
\hline GIACA2 & & & & & .912 & & \\
\hline GIACA3 & & & & & .842 & & \\
\hline DONGCAM3 & & & & & & .728 & \\
\hline DONGCAM4 & & & & & & .738 & \\
\hline DONGCAM5 & & & & & & .752 & \\
\hline TINCAY3 & & & & & & & .841 \\
\hline TINCAY6 & & & & & & & .806 \\
\hline
\end{tabular}




\begin{tabular}{|l|c|c|c|c|c|c|c|} 
TINCAY7 & & & & & & & .587 \\
\hline Eigenvalue & 5739 & 3450 & 2276 & 1856 & 1548 & 1362 & 1128 \\
\hline $\begin{array}{l}\text { Phương sai trích } \\
(\%)\end{array}$ & 11669 & 10994 & 10685 & 9922 & 9003 & 8999 & 8163 \\
\hline $\begin{array}{l}\text { Cronbach's } \\
\text { Alpha }\end{array}$ & 0.788 & 0.825 & 0.908 & 0.784 & 0.783 & 0.743 & 0.708 \\
\hline
\end{tabular}

Kết quả phân tích nhân tố khám phá các thang đo sự thỏa mãn của khách hàng và lòng trung thành dịch vụ ADSL tại TPHCM cho thấy tất cả 08 biến quan sát trong 02 thành phần vẫn giữ nguyên 02 nhân tố. Hệ số $\mathrm{KMO}=0.691$ nên $\mathrm{EFA}$ phù hợp với dữ liệu và thống kê, Chi-quare của kiểm định Bertlett đạt giá trị 593.164 với mức ý nghĩa 0.000 ; do vậy các biến quan sát có tương quan với nhau xét trên phạm vi tổng thể; Phương sai trích $57.450 \%$ thể hiện rằng 2 nhân tố rút ra được giải thích $57.45 \%$ biến thiên của dữ liệu, tại hệ số eigenvalue bằng 2.098. Do vậy, các thang đo rút ra là chấp nhận được.

Bảng 6: Kết quả EFA đối với các thang đo sự thỏa mãn của khách hàng và lòng trung thành dịch vụ ADSL

\begin{tabular}{|l|c|c|}
\hline \multirow{2}{*}{\multicolumn{1}{|c|}{ BIẾN QUAN SÁT }} & \multicolumn{2}{|c|}{ NHÂN Tố } \\
\cline { 2 - 3 } & THOAMAN (1) & TRUNGTHANH (2) \\
\hline THOAMAN1 & .865 & \\
\hline THOAMAN2 & .778 & \\
\hline THOAMAN3 & .770 & .705 \\
\hline THOAMAN4 & .707 & .768 \\
\hline TRUNGTHANH1 & & .789 \\
\hline TRUNGTHANH2 & & .632 \\
\hline TRUNGTHANH3 & & 2.498 \\
\hline TRUNGTHANH4 & 2.098 & 26.794 \\
\hline Eigenvalue & 30.656 & .701 \\
\hline Phương sai trích (\%) & .776 & \\
\hline Cronbach's Alpha & & \\
\hline
\end{tabular}

Kết quả thu được từ độ tin cậy Cronbach's Alpha và phân tích nhân tố khám phá cho thấy thang đo các khái niệm nghiên cứu đều đạt yêu cầu về độ giá trị và độ tin cậy. Mô hình nghiên cứu điều chỉnh được trình bày trong hình 4 bao gồm 7 biến độc lập và 2 biến phụ thuộc.

Hình 4: Mô hình nghiên cứu điều chỉnh từ kết quả EFA

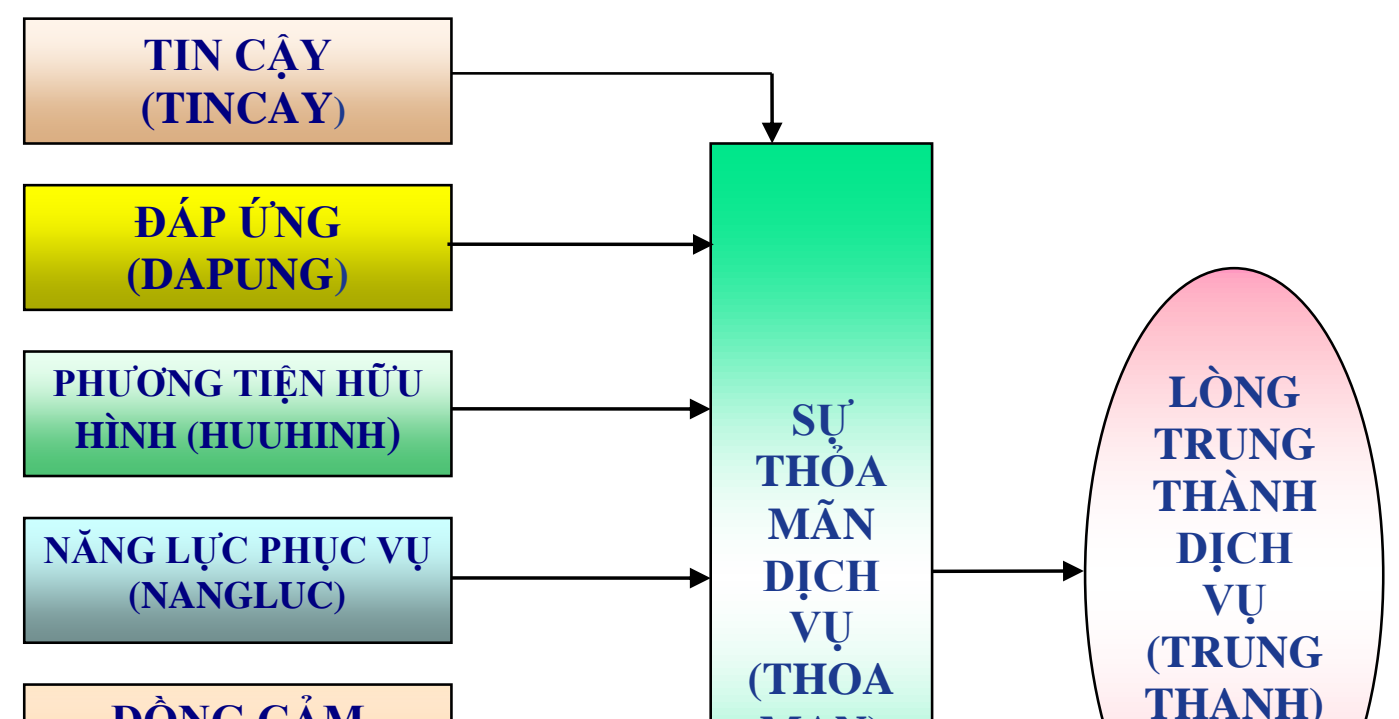




\section{Phân tích hồi quy}

Phương pháp thực hiện hồi quy là đưa vào lần lượt (Enter). Có 2 mô hình hồi quy cần thực hiện: mô hình thứ nhất (hồi quy đa biến) nhằm xác định vai trò quan trọng của từng nhân tố cảm nhận giá cả và chất lượng dịch vụ đối với sự thỏa mãn của khách hàng; mô hình thứ hai (hồi quy đơn biến) nhằm xác định sự tác động của sự thỏa mãn của khách hàng đến lòng trung thành của khách hàng.

Kết quả hồi quy tuyến tính bội cho thấy hệ số xác định $\mathrm{R}^{2}$ là 0.894 và $\mathrm{R}^{2}$ điều chỉnh là 0.891 , nghĩa là mô hình đã giải thích được $89.1 \%$ sự biến thiên của biến phụ thuộc sự thỏa mãn của khách hàng.

Bảng 7: Mô hình hồi quy đa biến đầy đủ

\begin{tabular}{|c|c|c|c|c|c|}
\hline MÔ HİNH & $\mathrm{R}$ & R Square & $\begin{array}{c}\text { ĐIỀU CHỈNH } \\
\text { R Square }\end{array}$ & $\begin{array}{c}\text { SAI SỐ ƯớC } \\
\text { LƯợNG }\end{array}$ & Durbin-Watson \\
\hline 1 & $.946^{\mathrm{a}}$ & .894 & .891 & .09377 & 1.806 \\
\hline
\end{tabular}

Bảng 8 cho thấy trị số thống kê $\mathrm{F}$ đạt giá trị 338.575 được tính từ giá trị $\mathrm{R}^{2}$ của mô hình đầy đủ, tại mức ý nghĩa Sig $=0.000$; kiểm tra hiện tượng tương quan bằng hệ số Durbin - Watson $(1<1.806<3)$. Như vậy, mô hình hồi quy tuyến tính bội phù hợp với dữ liệu nghiên cứu.

Bảng 8: Phân tích ANOVA

\begin{tabular}{|c|c|c|c|c|c|c|}
\hline \multicolumn{2}{|c|}{ MÔ HİNH } & $\begin{array}{c}\text { Tổng các độ } \\
\text { lệch bình } \\
\text { phương }\end{array}$ & df & $\begin{array}{l}\text { Bình quân } \\
\text { độ lệch }\end{array}$ & $\mathrm{F}$ & Sig. \\
\hline & HỒI QUI & 20.838 & 7 & 2.977 & 338.575 & $.000^{\mathrm{a}}$ \\
\hline 1 & SỐ DU & 2.471 & 281 & .009 & & \\
\hline & TỔNG & 23.309 & 288 & & & \\
\hline
\end{tabular}

Bảng 9 cho thấy cả 6 nhân tố thuộc chất lượng dịch vụ ADSL và nhân tố cảm nhận giá cả đều có tác động dương (hệ số Beta dương) đến sự thỏa mãn của khách hàng với mức ý nghĩa $\mathrm{Sig}=0.000$ ở tất cả các biến, ngoại trừ nhân tố DONGCAM với mức Sig 0.202 , cần được cân nhắc khi đưa vào mô hình.

Bảng 9: Các thông số của từng biến trong phương trình hồi quy thứ 1 


\begin{tabular}{|c|c|c|c|c|c|c|c|c|}
\hline \multirow[t]{2}{*}{$\begin{array}{l}\text { Mô } \\
\text { hình }\end{array}$} & \multirow[t]{2}{*}{ Nhân tố } & \multicolumn{2}{|c|}{$\begin{array}{l}\text { Hệ số chưa } \\
\text { chuẩn hoá }\end{array}$} & \multirow{2}{*}{$\begin{array}{c}\begin{array}{c}\text { Hệ số } \\
\text { chuẩn } \\
\text { hoá }\end{array} \\
\text { Beta }\end{array}$} & \multirow[t]{2}{*}{$\mathbf{t}$} & \multirow[t]{2}{*}{ Sig. } & \multicolumn{2}{|c|}{$\begin{array}{c}\text { Thống kê cộng } \\
\text { tuyến }\end{array}$} \\
\hline & & B & $\begin{array}{l}\text { Std. } \\
\text { Error }\end{array}$ & & & & $\begin{array}{c}\text { Dung } \\
\text { sai }\end{array}$ & VIF \\
\hline \multirow[t]{8}{*}{1} & (Constant) & 0.530 & 0.064 & & 8.28 & 0.000 & & \\
\hline & HUUHINH & 0.144 & 0.015 & 0.240 & 9.348 & 0.000 & 0.574 & 1.741 \\
\hline & TINCAY & 0.091 & 0.010 & 0.198 & 8.951 & 0.000 & 0.771 & 1.297 \\
\hline & GIACA & 0.174 & 0.012 & 0.309 & 14.269 & 0.000 & 0.804 & 1.244 \\
\hline & NANGLUC & 0.157 & 0.009 & 0.371 & 17.389 & 0.000 & 0.828 & 1.208 \\
\hline & GTGT & 0.134 & 0.007 & 0.377 & 18.897 & 0.000 & 0.947 & 1.057 \\
\hline & DONGCAM & 0.012 & 0.009 & 0.030 & 1.280 & 0.202 & 0.707 & 1.415 \\
\hline & DAPUNG & 0.126 & 0.014 & 0.219 & 9.264 & 0.000 & 0.675 & 1.481 \\
\hline
\end{tabular}

Do đó, phương trình hồi quy thứ nhất đối với các biến có hệ số chưa chuẩn hoá có dạng: THOAMAN $=0.530+0.144 *$ HUUHINH $+0.157 *$ NANGLUC $+0.134 *$ GTGT + 0.126*DAPUNG + 0.174*GIACA + 0.012*DONGCAM + 0.091*TINCAY

Bảng 10 cho biết kết quả hồi quy tuyến tính đơn biến, hệ số xác định $\mathrm{R}^{2}$ là 0.101 và $\mathrm{R}^{2}$ điều chỉnh là 0.098 , đạt yêu cầu đối với hồi quy đơn biến (hay mô hình đã giải thích được $9.8 \%$ sự biến thiên của biến phụ thuộc lòng trung thành dịch vụ).

Bảng 10: Mô hình hồi quy đơn biến đầy đủ

\begin{tabular}{|l|c|r|r|r|r|}
\hline $\begin{array}{c}\text { MÔ } \\
\text { HİNH }\end{array}$ & $\mathrm{R}$ & $\begin{array}{c}\text { HẸ SỐ XÁC } \\
\text { ĐỊNH R }\end{array}$ & $\begin{array}{c}\text { HỆ SỐ ĐIỀU } \\
\text { CHİNH R }\end{array}$ & $\begin{array}{c}\text { SAI SỐ ƯớC } \\
\text { LƯợNG }\end{array}$ & Durbin-Watson \\
\hline 1 & $.318^{\mathrm{a}}$ & .101 & .098 & .59033 & 1.224 \\
\hline
\end{tabular}

Bảng 11 cho thấy trị số thống kê $\mathrm{F}$ đạt 32.213 được tính từ giá trị $\mathrm{R}^{2}$ của mô hình đầy đủ, tại mức ý nghĩa $\mathrm{Sig}=0.000$, kiểm tra hiện tượng tương quan bằng hệ số Durbin-Watson $(1<1.224<3)$. Mô hình hồi quy đơn biến đưa ra là phù hợp với dữ liệu nghiên cứu.

Bảng 11: Phân tích ANOVA

\begin{tabular}{|c|c|c|c|c|c|c|}
\hline & MÔ HİNH & $\begin{array}{l}\text { Tổng các độ } \\
\text { lệch bình } \\
\text { phương }\end{array}$ & df & $\begin{array}{c}\text { Bình quân độ } \\
\text { lệch }\end{array}$ & $\mathrm{F}$ & Sig. \\
\hline \multirow[t]{3}{*}{1} & HỒI QUI & 11.226 & 1 & \multirow{3}{*}{$\begin{array}{r}11.226 \\
.348\end{array}$} & \multirow[t]{3}{*}{32.213} & \multirow[t]{3}{*}{$.000^{\circ}$} \\
\hline & SỐ DU' & 100.018 & 287 & & & \\
\hline & TỔNG & 111.244 & 288 & & & \\
\hline
\end{tabular}

Bảng 12 cho thấy nhân tố sự thỏa mãn khách hàng có tác động dương đến lòng trung thành dịch vụ $\mathrm{ADSL}$ với mức ý nghĩa $\mathrm{Sig}=0.000$. Phương trình hồi quy thứ hai đối với các biến có hệ số chưa chuẩn hoá có dạng: TRUNGTHANH $=1.339+0.625 *$ THOANMAN

Bảng 12: Các thông số của từng biến trong phương trình hồi quy thứ 2

\begin{tabular}{|c|c|c|c|c|c|c|}
\hline $\begin{array}{l}\text { Mô } \\
\text { hình }\end{array}$ & Nhân tố & $\begin{array}{l}\text { Hệ số chưa } \\
\text { chuẩn hoá }\end{array}$ & $\begin{array}{c}\text { Hệ số } \\
\text { chuẩn } \\
\text { hoá }\end{array}$ & $\mathbf{t}$ & Sig. & $\begin{array}{l}\text { Thống kê } \\
\text { công tuyến }\end{array}$ \\
\hline
\end{tabular}




\begin{tabular}{|c|c|c|c|c|c|c|c|c|}
\hline & & B & $\begin{array}{c}\text { Std. } \\
\text { Error }\end{array}$ & Beta & & & $\begin{array}{c}\text { Dung } \\
\text { sai }\end{array}$ & VIF \\
\hline \multirow[t]{2}{*}{1} & (Constant) & 1.339 & 0.389 & & 3.447 & 0.001 & & \\
\hline & THOAMANA & 0.625 & 0.110 & 0.318 & 5.676 & 0.000 & 1.000 & 1.000 \\
\hline
\end{tabular}

Phân tích tầm quan trọng các yếu tố theo giá trị trung bình

Theo bảng 13, các giá trị Mean cho thấy khách hàng đánh giá khá cao 4 yếu tố chất lượng dịch vụ: Cảm nhận giá cả, Độ Tin cậy, Phương tiện hữu hình, Sự đáp ứng, đánh giá trung bình khá 3 yếu tố: Năng lực phục vụ, Sự đồng cảm, Giá trị gia tăng tiện ích. Nhìn chung, khách hàng đánh giá tương đối tốt các yếu tố chất lượng dịch vụ và cảm nhận giá cả nên sự thỏa mãn của khách hàng cũng khá cao.

Bảng 13: Giá trị trung bình của chất lượng dịch vụ và cảm nhận giá cả

\begin{tabular}{|l|c|c|c|}
\hline \multicolumn{1}{|c|}{ NHÂN TỐ } & $\begin{array}{c}\text { GÍA TRI } \\
\text { TRUNG } \\
\text { BİNH }\end{array}$ & Độ LẸCH CHUÂN & $\begin{array}{c}\text { SAI SỐ CHUÂN } \\
\text { TRUNG BİNH }\end{array}$ \\
\hline GIACA & 3.9550 & .50451 & .02968 \\
DAPUNG & 3.8097 & .49576 & .02916 \\
HUUHINH & 3.7910 & .47470 & .02792 \\
TINCAY & 3.6990 & .61592 & .03623 \\
DONGCAM & 3.3633 & .71677 & .04216 \\
NANGLUC & 3.0770 & .67243 & .03955 \\
GTGT & 2.9135 & .80064 & .04710 \\
\hline
\end{tabular}

Hình 5 cho thấy giá trị trung bình của sự thỏa mãn của khách hàng với Mean $=3.786$, và lòng trung thành dịch vụ $\mathrm{ADSL}$ với Mean $=3.536$, cho thấy khách hàng thỏa mãn khá cao với chất lượng dịch vụ $\mathrm{ADSL}$ đang sử dụng, và từ đó lòng trung thành của họ với dịch vụ này cũng khá cao.

Hình 5: Giá trị trung bình của sự thỏa mãn khách hàng và trung thành dịch vụ

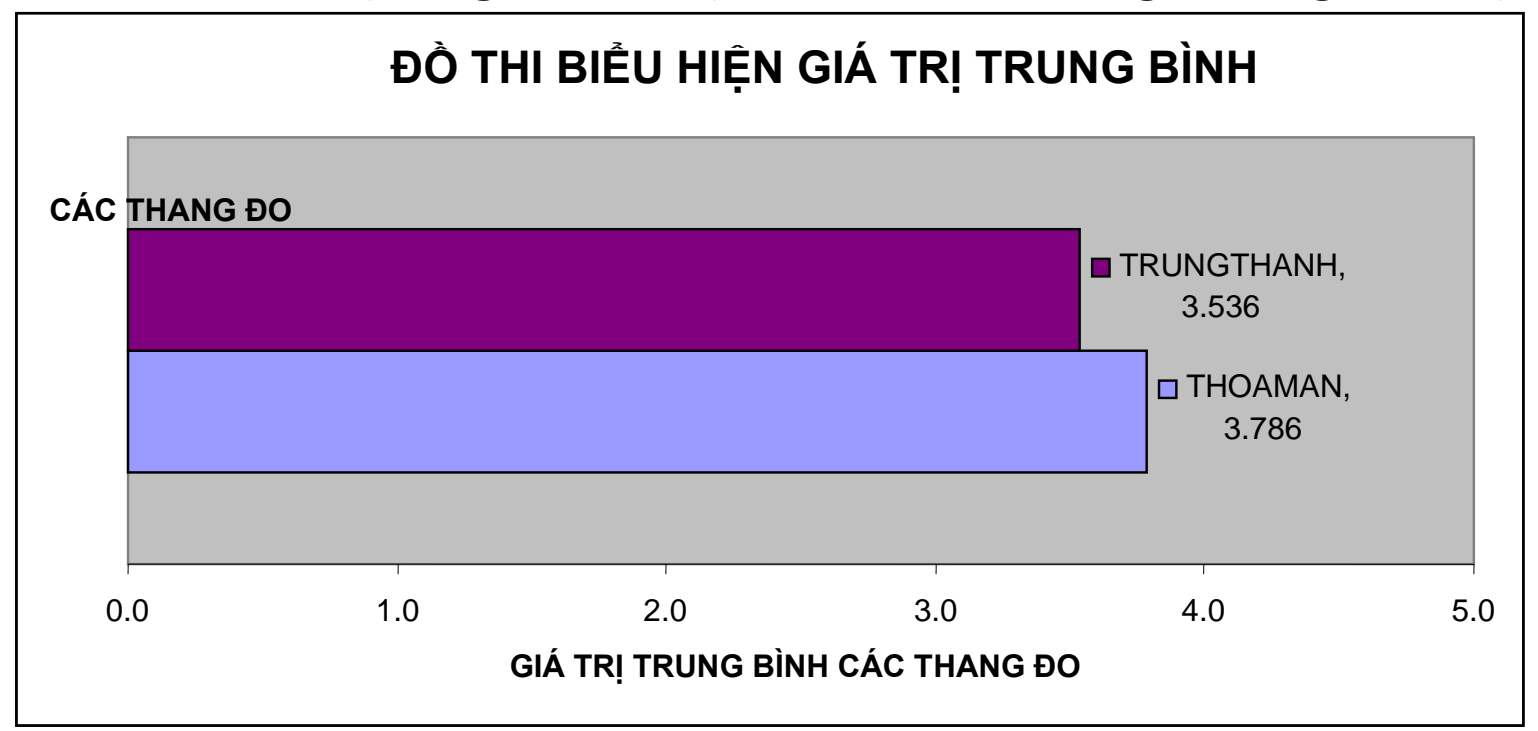

\section{KẾT LUẬN VÀ CÁC KIẾN NGH! \\ Kết luận}

Kết quả nghiên cứu cho thấy có 7 yếu tố tác động đến sự thỏa mãn của khách hàng sử dụng ADSL tại TPHCM, tuy nhiên chỉ có 6 yếu tố là có quan hệ nhân quả với Sự thỏa mãn 
của khách hàng, trong đó Cảm nhận Giá cả có tác động lớn nhất, tiếp theo lần lượt là Năng lực phục vu, Phương tiện hưu hình, Giá trị gia tăng và Độ Đáp ứng, Độ Tin cậy. Độ Đồng cảm chưa bị loại ra khỏi phương trình hồi qui, nhưng có mức Sig cao. Kết quả cũng cho thấy Lòng trung thành của khách hàng cũng chịu tác động của Sự thỏa mãn khách hàng sử dụng dịch vụ ADSL tại TPHCM, dù mức tác động chỉ đạt $9.8 \%$.

Kết quả nghiên cứu cũng cho thấy khách hàng đánh giá khá cao các yếu tố chất lượng dịch vụ, cảm nhận giá cả, sự thỏa mãn, và lòng trung thành, trong đó Giá trị gia tăng được đánh giá thấp nhất, kế đến là Nămg lực phục vu, Độ Đồng cảm, Độ Tin cậy, Phwơng tiện Hũu hình và Độ Đáp ứng, được đánh giá cao nhất là Cảm nhận giá cả.

Qua đó, có thể nhận định rằng các doanh nghiệp cung cấp dịch vụ $\mathrm{ADSL}$ đã làm khá tốt chất lượng dịch vụ và gía cả, và chính các yếu tố này có tác động lớn đến sự thỏa mãn, từ đó tác động đến lòng trung thành của khách hàng sử dụng ADSL tại TPHCM. Kết quả của nghiên cứu này cũng giúp cho ban lãnh đạo các doanh nghiệp cung cấp dịch vụ hiểu biết được sự đánh giá của khách hàng đối với chất lượng dịch vụ và giá cả dịch vụ; có thể đưa ra những chính sách phù hợp, đúng đắn cho các bộ phận liên quan. Nghiên cứu cũng đưa ra một số kiến nghị nhằm cải thiện chất lượng dịch vụ ADSL để thỏa mãn khách hàng tốt hơn, nâng cao lòng trung thành.

\section{Một số giải pháp kiến nghị đến các doanh nghiệp}

Giá trị gia tăng tiện ích: doanh nghiệp cần tuyên truyền, quảng bá rộng rãi tiện ích của gói dịch vụ giá trị gia tăng, vì trong tương lai, những tiện ích này sẽ trở thành lợi thế cạnh tranh. Khi $3 \mathrm{G}$ được áp dụng rộng rãi như đường truyền di dộng, nhanh và rẻ, mọi doanh nghiệp viễn thông có lợi thế hạ tầng mạng viễn thông như nhau, doanh nghiệp nào phát huy được sự đa dạng của gói dịch vụ giá trị gia tăng tiện ích, khả năng tạo sự thỏa mãn của khách hàng cao hơn.

Năng lục phục vụ: doanh nghiệp cần thường xuyên đào tạo và tái đào tạo nhân viên của mình, cả về công nghệ mới lẫn các kỹ năng chăm sóc khách hàng. Ngoài ra, cần bổ sung những chính sách khuyến khích, động viên nhân viên để tạo động lực gắn kết của nhân viên với doanh nghiệp; điêù hành hợp lý giữa các phòng ban ngành, giúp đỡ các nhân viên có thể liên hệ giải quyết tốt mối quan hệ khách hàng.

Cảm nhận giá cả: doanh nghiệp cần có chính sách giá cước dịch vụ linh hoạt, phù hợp với từng phân khúc thị trường, nhằm giúp khách hàng tiềm năng tiếp cận với dịch vụ, giúp khách hàng hiện có hiểu biết chính sách khuyến mãi giá, đặc biệt chú ý đến các hình thức khuyến mãi sau bán hàng để khách hàng thỏa mãn và trung thành với dịch vụ hơn.

Phuơng tiện hũu hình: doanh nghiệp cần đầu tư các trang thiết bị hiện đại, nhiều điểm giao dịch khang trang, đồng phục nhân viên đẹp, thường xuyên cải tiến công nghệ và tung ra thị trường nhiều sản phẩm dịch vụ mới ..., cần thiết lập nhiều kênh thông tin để tiếp thu ý kiến khách hàng như: hộp thư góp ý, trang thông tin điện tử công ty, địa chỉ email tiếp nhận ý kiến, nhóm tiểp nhận ý kiến thường trực tại các điểm giao dịch, trung tâm hỗ trợ kỹ thuật qua điện thoại, hệ thống nhắn tin ngắn của điện di động (SMS)... để hỗ trợ kỹ thuật và báo hư sửa tốt cho khách hàng nhanh nhất.

Đáp úng dịch vụ: hiện nay, nhu cầu thị trường lắp đặt ADSL còn khá lớn nếu so sánh mật độ đã được lắp đặt trên số thuê bao điện thoại hiện có (tính đến tháng 7/2011, TPHCM có khoảng 859.724 thuê bao $\mathrm{ADSL}$ và 1,8 triệu thuê bao điện thoại cố định). (http://www.thongkeinternet.vn). Doanh nghiệp cần quan tâm, giám sát, kiểm tra, đào tạo và có chính sách thích hợp với đội ngũ nhân viên thực hiện công tác lắp đặt, cài đặt dịch vụ nhằm mục tiêu đáp ứng nhanh chóng nhu cầu khách hàng.

Độ Tin cậy: doanh nghiệp cần thực hiện tốt công tác xử lý khiếu nại của khách hàng (chủ yếu là khiếu nại về cước), đảm bảo hồi âm cho việc khiếu nại của khách hàng trong vòng 24 giờ, cũng như nhanh chóng khắc phục sự cố. Doanh nghiệp cần lắng nghe ý kiến 
khách hàng, và cần thực hiện liên tục, từng giờ, từng ngày, trong tất cả thời gian tiếp xúc với khách hàng.

Sụ đồng cảm: Nhanh chóng khắc phục sự cố cho khách hàng, giảm thời gian khắc phục sự cố nội thành < 10 giờ, ngoại thành, thị trấn < 20 giờ (tiêu chuấn nhà nước: nội thành $<24$ giờ, ngoại thành, thị trấn $<36$ giờ). Doanh nghiệp cần tập trung đào tạo thường xuyên nhân viên về các kỹ năng chăm sóc khách hàng nhằm cải thiện hình ảnh doanh nghiệp. Việc cải thiện, tạo động lực cho đội ngũ cán bộ công nhân viên bán hàng, chăm sóc và hỗ trợ khách hàng nên được tiến hành từ vấn đề lương thưởng, đào tạo, đồng thời đảm bảo những quyền lợi chính đáng cho bản thân nhân viên tiếp xúc và quản lý khách hàng.

Ngoài ra, các doanh nghiệp cũng có thể nghĩ đến việc thành lập Hiệp hội các nhà khai thác dịch vụ viễn thông, phối hợp cho thuê hạ tầng mạng lẫn nhau để tận dụng nguồn lực giữa các nhà khai thác viê̂n thông, tiết kiệm việc đầu tư các cơ sở hạ tầng chồng chéo và không hiệu quả.

\section{TÀI LIỆ THAM KHẢO}

Bartels, F. L., Giao, H. N. K., \& Ohlenburg, T. J. (2006). ASEAN Multinational Entreprises: A Structural Analysis of Strategic Coherence. ASEAN Economic Bulletin, 23(2), 171191. doi:10.1355/AE23-2C

Cronin, J J., \& Taylor, S.A., (1992), "Measuring Service Quality: A Reexamination and Extension", Journal of Marketing, 56 (July): 55-68.

Giao, H. N. K. (1996a). Hương dẫn tóm tắt Chiến lược Công ty. Thành phố Hồ Chí Minh: Nhà Xuất bản Thống kê.

Giao, H. N. K. (1996b). Quản trị Tiếp thị Toàn cầu. Thành phố Hồ Chí Minh: Nhà Xuất bản Thống kê.

Giao, H. N. K. (2004a). Diến thuyết trước Công chúng-Làm sao để thu hút Khán giả? Thành phố Hồ Chí Minh: Nhà Xuất bản Thống kê.

Giao, H. N. K. (2004b). Kỹ năng làm việc - Skills for Success (S4S) (Vol. 2): Nhà Xuất bản Thống kê.

Giao, H. N. K. (2004c). Kỹ năng làm việc-Skills for Success (S4S) (Vol. 1). Thành phố Hồ Chí Minh: Nhà Xuất bản Thống kê.

Giao, H. N. K. (2004d). Kỹ năng Thương lương- 7 buớc RESPECT. Thành phố Hồ Chí Minh: Nhà Xuất bản Thống kê.

Giao, H. N. K. (2004e). Marketing Công nghiệp- Phục vụ Khách hàng là các Tổ chúc. Thành phố Hồ Chí Minh: Nhà Xuất bản Thống kê.

Giao, H. N. K. (2004f). Marketing Dịch vụ-Mồ hình 5 Khoảng cách Chất lương Dịch vụ. Thành phố Hồ Chí Minh: Nhà Xuất bản Thống kê.

Giao, H. N. K. (2004g). Marketing Dịch vu- Phục vụ Khách hàng tốt hơn. Thành phố Hồ Chí Minh: Nhà Xuất bản Thống kê.

Giao, H. N. K. (2004h). Quan hệ Công chúng- Để người khác gọi ta là PR. Thành phố Hồ Chí Minh: Nhà Xuất bản Thống kê.

Giao, H. N. K. (2004i). Quản trị Bán hàng- Đội ngũ Bán hàng tốt chưa? . Thành phố Hồ Chí Minh: Nhà Xuất bản Thống kê.

Giao, H. N. K. (2004j). Quản trị Chiến lược Công ty-Phát huy Tiềm lực Cạnh tranh (Vol. 2). Thành phố Hồ Chí Minh: Nhà Xuất bản Thống kê.

Giao, H. N. K. (2004k). Quản trị Chiến lược Công ty-Phát huy Tiềm lục Cạnh tranh (Vol. 1). Thành phố Hồ Chí Minh: Nhà Xuất bản Thống kê.

Giao, H. N. K. (20041). Quản trị Công ty Đa quốc gia-Quản lý tù sụ đa dạng Văn hóa (Vol. 2). Thành phố Hồ Chí Minh: Nhà Xuất bản Thống kê.

Giao, H. N. K. (2004m). Quản trị Công ty Đa quốc gia- Quản lý tù̀ sụ đa dạng Văn hóa (Vol. 1). Thành phố Hồ Chí Minh: Nhà Xuất bản Thống kê. 
Giao, H. N. K. (2004n). Quản trị học- Để Quản lý không còn là quá khó (Vol. 2). Thành phố Hồ Chí Minh: Nhà Xuất bản Thống kê.

Giao, H. N. K. (2004o). Quản trị hoc- Để Quản lý không còn là quá khó (Vol. 1). Thành phố Hồ Chí Minh: Nhà Xuất bản Thống kê.

Giao, H. N. K. (2004p). Quản trị Marketing-Marketing để Chiến thắng. Thành phố Hồ Chí Minh: Nhà Xuất bản Thống kê.

Giao, H. N. K. (2010a). Đo lường chất lượng dịch vụ tiền gửi tiết kiệm tại Agribank- Phương pháp so sánh các chỉ tiêu. Tạp chí Ngân hàng, Ngân hàng Nhà nước VN, 20, 21-28. doi:10.31219/osf.io/afskm

Giao, H. N. K. (2010b). Mạn đàm thước đo Văn hóa Doanh nghiệp trong các Ngân hàng thương mại. Tạp chí Ngân hàng, Ngân hàng Nhà nước VN, 22, 25-27. doi:10.31219/osf.io/rtqz4

Giao, H. N. K. (2010c). Một số vấn đề qua khảo sát giá chuyển nhượng của các doanh nghiệp có vốn đầu tư nước ngoài tại Việt Nam. Tạp chí Ngân hàng, Ngân hàng Nhà nước VN, 18, 65-69. doi:10.31219/osf.io/b24hk

Giao, H. N. K. (2011a). Độ hài lòng của khách hàng sử dụng thẻ thanh toán tại Thành phố Hồ Chí Minh. Tạp chí Công nghệ Ngân hàng- Truò̀ng Đại học Ngân hàng TPHCM, 24-31. doi:10.31219/osf.io/g2bjq

Giao, H. N. K. (2011b). Giáo trình Marketing Du lịch. Thành phố Hồ Chí Minh: Nhà xuất bản Tổng hợp

Giao, H. N. K. (2011c). Mức độ hài lòng của khách hàng sử dụng thẻ thanh toán tại Thành phố Hồ Chí Minh. Tạp chí Khoa học Đào tạo Ngân hàng-Học viện Ngân hàng, 111, 24-30. doi:10.31219/osf.io/83fgr

Giao, H. N. K., \& Bình, N. V. (2011). Giáo trình Nghiệp vụ Nhà hàng. Thành phố Hồ Chí Minh: Nhà xuất bản Tổng hợp.

Giao, H. N. K., \& Duy, H. B. (2009). Measuring service quality of outsourcing software at Quantic Co., Ltd- a dimension-by dimension approach. Journal of Sciences and Technology Development, , 12, 56-70. doi:10.31219/osf.io/n8r73

Giao, H. N. K., \& Hà, B. L. (2009). Khảo sát việc tuân thủ các qui định về định giá chuyển nhượng của các doanh nghiệp có vốn đầu tư nước ngoài tại Việt Nam. Tạp chí Phát triển Kinh tế, 225, 28-33. doi:10.31219/osf.io/ht26y

Giao, H. N. K., \& Hà, D. N. (2011). Measuring service quality at Wan Hai Lines outbound services. Journal of Economic Development, 200, 24-34. doi:10.31219/osf.io/8d6bn

Giao, H. N. K., \& Hằng, L. D. (2011). Các yếu tố tác động đến độ thỏa mãn về chất lượng dịch vụ khoa khám chữa bệnh theo yêu cầu tại bệnh viện Thống Nhất Thành phố Hồ Chí Minh. Tạp chí Phát triển Kinh tế, 252, 44-53. doi:10.31219/osf.io/xpz5s

Giao, H. N. K., \& Hào, N. H. (2011). Đo lường chất lượng dịch vụ tại resort Whitesand. Tạp chí Nghiên cứu Tài chính-Marketing, 3, 56-65. doi:10.31219/osf.io/57kdr

Giao, H. N. K., \& Hương, Đ. T. (2010). Các nhân tố tác động đến định hướng khách hàng của nhân viên phục vụ khách sạn Thành phố Hồ Chí Minh. Tạp chí Nghiên cứu Tài chính-Marketing, 1, 24-34. doi:10.31219/osf.io/n6mxu

Giao, H. N. K., \& Phương, V. T. M. (2011). Đo lường sự thỏa mãn công việc của nhân viên sản xuất tại công ty TNHH TM-DV Tân Hiệp Phát. Tạp chí Phát triển Kinh tế, 6, 1521. doi:10.31219/osf.io/uwcae

Giao, H. N. K., \& Thi, T. N. (2011). Các nhân tố tác động đến chất lượng chuỗi nhà thuốc tại Thành phố Hồ Chí Minh. Tạp chí Công nghiệp- Đại học Công nghiệp TPHCM, 5, 5768. doi:10.31219/osf.io/8jwaf

Giao, H. N. K., \& Tú, P. T. N. (2010). Đánh giá Chất lượng dịch vụ Ngân hàng điện tử tại Việt Nam. Tạp chí Ngân hàng, Ngân hàng Nhà nước VN, 18, 20-28. doi:10.31219/osf.io/tr6k4 
Giao, H. N. K., \& Vũ, N. T. (2011). Sự thỏa mãn khách hàng về chất lượng dịch vụ siêu thị Vinatex-mart. Tạp chí Phát triển Kinh tế, 253, 9-16. doi:10.31219/osf.io/r7xfe

Gremler, D. D., \& Brown, S. W. (1996). Service loyalty: its nature, importance and implications', in Edvardsson, B., Brown, S.W., Johnston, R. and Scheuing, E.E. (Eds), Proceedings American Marketing Association, pp. 171-180. in Caruana, A. (2000). "Service loyalty- the effects of service quality and mediating role of customer satisfaction," European Journal of Marketing, 36 (7/8), 811-823.

Lassar, W. M., Manolis C. \& Winsor R.D., (2000), "Service Quality Perspectives and Satisfaction in Private Banking”, International Journal of Bank Marketing, 14 (3): 244-271.

Nunnally, J., \& I. H. Bernstein (1994), Pschychometric Theory, 3rd ed., McGraw-Hill, New York.

Parasuraman, A., Zeithaml, V., \& Berry L. (1985). A conceptual model of service quality and its implications for future research. Journal of Marketing, 49, 41-50.

Parasuraman, A., L. L. Berry, \& V. A. Zeithaml (1991). Refinement and Reassessment of the SERVQUAL Scale. Journal of Retailing, 67(4), 420-450.

Too, L. H. Y, Souchon, A. L., Thirkell, P. C. (2001). Relationship marketing and customer loyalty in a retail setting: a dyadic exploration. Journal of Marketing Management, 17, 287-320.

Zeithaml, V. A., Berry, L. L., \& Parasuraman, A. (1996). The behavioral consequences of service quality. Journal of Marketing; 60, 31-46.

Zeithaml, V.A \& Bitner, M.J (2000). Services Marketing: Integrating Customer Focus Across the Firm. Irwin McGraw-Hill. 